\title{
Social Capital and Willingness-to-Pay for Community-Based Health Insurance in Rural Cameroon
}

\author{
Hermann Pythagore Pierre Donfouet (Corresponding author) \\ Faculty of Economics and Management, University of Yaounde II-Soa \\ PO Box 1365, Yaounde, Cameroon \\ Tel: 237-7555-7201 E-mail: donfouetz@yahoo.fr \\ Jean-Roger Edimo Essombè \\ Faculty of Economics and Management, University of Yaounde II-Soa \\ PO Box 1365, Yaounde, Cameroon \\ Tel: 237-9975-0790 E-mail: jressombe@yahoo.fr \\ Pierre-Alexandre Mahieu \\ Faculty of Economics, University of Rouen \\ P.O Box: 3, Avenue Pasteur 76186 Rouen, France \\ Tel: 33-(0)-2-276-9670Ｅ-mail: pamahieu@gmail.com
}

Eric Malin

Faculty of Economics, University of Rennes I, France

PO Box 7 Place Hoche, 35065 Rennes Cedex, France

Tel: 33-(0)-2-2323-3364Ｅ-mail: Eric.Malin@univ-rennes1.fr

Received: December 6, 2010 Accepted: December 20,2010 doi:10.5539/gjhs.v3n1p142

This work benefits from the financial and scientific support from the International Labor Organization (ILO) (Geneva) and from the African Population and Health Research Centre (APHC).The authors would like to thank Professor Jean-Phillipe Plateau, Professor Joseph Cook, Aurélia Lépine, Alexis Le Nestour and the European Development Research Network (EUDN) (Namur) resource persons for helpful discussions. Any error or omission remains the authors'sole responsibility.

\begin{abstract}
Community-based health insurance in developing countries is often perceived as a way to improve the health state of rural households. An open question is whether the social capital has a positive impact on the demand for health insurance. A contingent valuation study was conducted to explore the influence of the social capital on the demand for health insurance. The main results are that (i) most of the rural households are willing to pay for community-based health insurance (ii) the social capital has a positive impact on the willingness to pay for community-based health insurance. The policy implications of the results are discussed.
\end{abstract}

Keywords: Community-based health insurance, Contingent valuation, Social capital

\section{Introduction}

Poor households living in Cameroon rural areas do not have access to medical care due to lack of income and/or medical facilities (Matul et al. 2009). When getting sick, they typically try to borrow money or sell their properties. Another alternative for them is community-based health insurance. The involvement of the community in health financing was spurred, among others, by the Declaration of Alma Ata in 1978 (Bose and Desai 1983), urging maximum community participation in organization of primary health care (Carrin et al. 2005). The importance of community-based health insurance emanates from the limitations of conventional 
health insurance to protect the poor from all sorts of events. It has three main features: prepayment for health services by community members; community control; and voluntary membership (Hsiao 2001). Major international development agencies often consider community-based health insurance as an effective mechanism to achieving universal coverage for health care in poor countries (Gottret and Schieber 2006; WHO 2005). There is a growing interest in (i) knowing the premiums that poor people would pay to join this type of low-cost health insurance and (ii) assessing the impact of the social capital on the demand for community-based health insurance.

Dror et al. (2007) study households' Willingness-To-Pay (WTP) for health insurance in a large bidding game survey conducted in India (3,000 households). About half of the sample is willing to pay at least $1.35 \%$ of annual household income and a positive link between households' income and WTP is found. Furthermore, in another study, Asgary et al. (2004) show that rural households in rural Iran are willing to pay on average US\$2.77 per month for health insurance. Nevertheless, very few studies have examined so far the influence of the social capital on the demand for community-based health insurance. Popularized by Putnam (1993), a good number of researchers and international organizations have put in place some tidemarks to measure social capital. Their approach treats the social capital as a dependent variable. Recently, an alternative way has been developed and it mainly consists of studying the role or the impact (contribution) of social capital on health, environmental protection. Hence, the social capital is studied as an explanatory variable. The concept of social capital emerged from Sociology (see e.g., Portes 1998; Putnam 2000) where it is associated to concepts like social networks, reciprocity, trustworthiness, and civic engagement. Social capital can be defined as: "...investment and use of embedded resources in social relations for expected returns" (Lin 2000, p.786). Social capital is increasingly recognized as having a positive effect on health status (Coleman 1990; Putnam et al. 1993; Wilkinson 1996) and there are still active research activities on this link. Recent research typically shows that a low level of trust among citizens leads to a high mortality rate (Baum 1997; Kawachi et al. 2004). Moreover, trust in the community facilitates cooperation, gives access to support, aid and care services that is provided by informal institutions which are mainly based on reciprocity. This informal institution provides health insurance to the poor. By showing solidarity, poor groups may indirectly increase their income and social well being (Flores and Rello 2003). There is no consensus in the literature on how social capital ought to be measured (Note 1), mainly because there is a large variety of social capital. Social capital can refer to a social group or an individual asset; it can be informal or mediated by formal institutions; it can be inclusive or exclusive.

Several studies have demonstrated that a high social capital in the community increases the chance for the community-based health insurance to be successful (Woolcock 2001; Woolcock and Narayan 2006). Hence, examining the influence of the social capital on the demand for community-based health insurance can provide precious information to policymakers when promoting or establishing community-based health insurance in rural areas. The main objective of this paper is to investigate the influence of the social capital on the WTP for community-based health insurance. The remainder of the paper is organized as follows. Section 2 presents the methodology used, while section 3 focuses on the questionnaire. Section 4 considers the empirical results of the study and section 5 concludes with some policy implications.

\section{Econometric model}

Proposed by Davis (1963), the contingent valuation method has been used in many areas including environment, health, transport and marketing and has proven to be a useful instrument to provide information on people's preferences for non-marketed goods. The contingent valuation method which belongs to the family of the stated preference techniques is a "survey-based method frequently used for placing monetary values on environmental goods and services not bought and sold in the marketplace" (Carson 2000, p.1413). Over the last two decades, improvement has been made regarding the method, and some practice has been discarded, like the use of open-ended question to elicit WTP. Nowadays, the referendum format is often used (Bishop and Heberlein 1979; Hoehn and Randall 1987; Arrow et al. 1993). People are faced with a given payment, the payment amounts varying across participants, and they are to state whether they would accept to pay the assigned payment. This format which is incentive compatible and places a low cognitive burden on the participants has an important drawback: it provides little information on the WTP: just that the WTP is below or above the given payment. To overcome this issue, Hanemann et al. (1991) used a second payment, higher or lower to the first depending on the first response. When using this format the researcher can use both parametric and non-parametric approaches to estimate the mean WTP. Furthermore, the parametric approach can also be used to estimate the WTP function, i.e. the function that relates the respondent's characteristics to the WTP.

The econometric procedure follows Cameron (1988). An interval data regression is used to compute the WTP function and the mean WTP. Let $W T P_{i}$ denote the willingness-to-pay, $x_{i}$ a vector of explanatory variables 
including social capital and $\varepsilon_{i}$ a random component following a normal distribution with mean zero and standard deviation $\sigma$. Then, the equation to be estimated is:

$$
W T P_{i}=x_{i}^{\prime} \beta+\varepsilon_{i}
$$

In the study $W T P_{i}$ is unobserved, and there are three possible cases depending on the participants' yes/no answers to the valuation questions. (a) $W T P_{i}$ is inferior to a bid amount say $t_{l}$, (b) $W T P_{i}$ is superior to a bid amount, say $t_{u}$ (c) $W T P_{i}$ is between two bid amounts $t_{l}$ and $t_{u}$. Situation (a) corresponds the case where the individual states "no" twice (the second bid amount is $t_{l}$ ) while situation (b) corresponds to the case where the individual states "yes" twice (the second bid amount is $t_{u}$ ). Finally, situation (c) is the case where the individual states "yes" and "no", regardless of the order (the higher and lower bid amounts are denoted $t_{u}$ and $t_{l}$ respectively). The probability associated to each case is the following:

$$
\begin{gathered}
\mathrm{P}\left(W T P_{i}<t_{l i}\right)=P\left(z_{i}<\frac{t_{l i}-x_{i}{ }^{\prime} \beta}{\sigma}\right)=\Phi\left(z_{l i}\right) \\
\mathrm{P}\left(t_{u i}<W T P_{i}\right)=P\left(\frac{t_{u i}-x_{i}{ }^{\prime} \beta}{\sigma}<z_{i}\right)=1-\Phi\left(z_{u i}\right) \\
\mathrm{P}\left(t_{l i}<W T P_{i}<t_{u i}\right)=P\left(\frac{t_{l i}-x_{i}{ }^{\prime} \beta}{\sigma}<z_{i}<\frac{t_{u i}-x_{i}{ }^{\prime} \beta}{\sigma}\right)=\Phi\left(z_{u i}\right)-\Phi\left(z_{l i}\right)
\end{gathered}
$$

The corresponding binary indicators are:

$I_{i}^{Y Y}=\mathbf{1}$ (the individual $i$ states "yes" twice),

$I_{i}^{N N}=\mathbf{1}$ (the individual $i$ states "no" twice),

$I_{i}^{Y N}=\mathbf{1}$ (the individual $i$ states "yes" and "no" irrespectively of the order),

where the function $\mathbf{1}($.$) takes value one when the argument is true and zero otherwise.$

The following log-likelihood function can be is maximized for $N$ independent observations to estimate both $\beta$ and $\sigma$ :

$$
\operatorname{Ln} L=\sum_{i=1}^{N}\left[I_{i}^{Y N} \cdot \ln \left(\Phi\left(z_{u i}\right)-\Phi\left(z_{l i}\right)\right)+I_{i}^{N N} \cdot \ln \left(\Phi\left(z_{l i}\right)\right)+I_{i}^{Y Y} \cdot \ln \left(1-\Phi\left(z_{u i}\right)\right]\right.
$$

The unconditional mean WTP, based on the parametric approach, corresponds to the intercept when all the explanatory variables have been removed from the model.

\section{Questionnaire}

In November 2009, 399 households living in a rural area of Cameroon (Bandjoun) were surveyed by trained interviewers. A two-stage cluster sampling was used. First, six villages were selected-based on population size and availability of health centres. Second, people in these villages were randomly picked. In an attempt to conduct a state-of-the-art contingent valuation, guidance provided in Arrow et al. (1993), Carson (2000), Carson et al. (2001), and Whittington $(1998,2002)$ were followed. Furthermore, a "consequentialism" (Note 2) script built on Bulte et al. (2005) was integrated to mitigate the tendency to overestimate WTP called hypothetical bias (Blumenschein et al., 2008) (Note 2). The wording of the script was as follows:

Many studies reveal that a good health status is a requirement to achieve some of the goals in life, like for instance building houses, bringing up children, having a good job etc. Nevertheless, people may, including you, fall sick and use various methods to treat themselves-such as borrowing money, selling belongings, visiting traditional healer/shaman or religious organization etc, meaning that they have to pay out-of pocket before using any health facility. If the individual fails to obtain any financial help, his health condition will deteriorate and he will probably die. Due to this, a trustworthy NGO plans to establish a health insurance scheme in your community so that you and your whole family (ten members at most) will be able to use health care services at any nearest public health centers. The following health services will be offered to you: diagnosis, laboratory tests, surgeries, drugs, delivery etc. If you decide to join such a system and be covered when you and your family are sick, you will pay a monthly amount as premium.

Before answering the questions below, consider the advantages associated with the proposed scheme, your monthly income, and also that, there are other things your money could be spent on. Note that the results of this study will be made available to policymakers, and could serve as a guide for future decisions. Before I proceed, do you have any question? 
Focus groups and pretests were conducted to set the bid amounts to be used in the final survey. The first payment was one of the following amounts: 250, 350, 450, 550, 650 and 800 CFA francs, the payment being randomly assigned to the respondents as recommended in Mitchell and Carson (1989). The second bid amount was half of the first bid if the respondent said "no" and twice if he said "yes". For instance, an individual stating "yes" to 350 CFA francs was asked whether he would pay 700 CFA francs in the second round. Focus groups and pretests were also used to ensure that the questionnaire was properly worded.

\section{Results}

\subsection{Descriptive statistics}

Table 1 provides descriptive statistics of the study, while Table 2 displays the response rate to both the first and second bid amounts respectively. As can be seen, only $8.52 \%$ of the participants stated "no" to both amounts, i.e. they stated "no" twice. This means that very few participants are not willing to pay for the program. Or, to say it differently, that most participants are willing to pay for the program.

Insert Table1 here.

Insert Table 2 here.

\subsection{Results of the parametric approach}

We use the interval data model Cameron (1988) to study the determinants of the WTP, and check, whether social capital affects WTP. As stated before, there is a major problem among social scientists on how to measure social capital. Nevertheless most of the existing definitions of the concept (Coleman 1988; Putnam et al.1993; Bowles and Gintis 2002) consider the association membership as one of the main component of the stock of social capital. Hence, in the current study, we focus on association memberships as a measure of individual's social capital, as in previous studies. We use an indicator of individual participation in local organizations denoted involvement. The variable involvement takes on the value 1 if the individual has been involved in a health policy before or is currently enrolled in an association ('jangy' or 'tontines') which aims at improving the heath state of his member.

Table 3 presents the results of the regression. As expected, the social capital has a positive impact on WTP. Most of the rural households involved in associations such as 'tontines' or 'jangy' have a higher WTP that those who are not ceteris paribus. The positive and significant coefficient of social capital reveals that the degree of community solidarity is an important factor in establishing a community-based health insurance. Hence, social capital has a positive and significant effect on the WTP for community-based health insurance. It is consistent with other studies (Hsiao 2001; Zhang et al. 2006) which show that social cohesion and solidarity facilitated collective action, which might increase willingness to pay for community-based health insurance. Income has a positive and statistically significant impact on WTP which is consistent with economic theory and increase the validity of our results. Furthermore, health status does not affect WTP for community-based health insurance. Gustafsson et al. (2009) found the same results in a case study conducted in Namibia and concluded to an absence of adverse selection. The coefficient age is significant at $5 \%$ level and positive implying that young people tend to have a higher WTP.

The coefficient related to religion is positive and statistically significant implying that Catholic household has a higher WTP than the rest of the participants. The households in the rural areas of Bandjoun who are more knowledgeable about community-based health insurance tend to have a higher WTP than their counterparts. Besides, the positive and significant coefficient of the usual means of seeking treatment implies that the household heads who regularly use the orthodox means of seeking treatment (clinics/hospitals) when they get sick are more willing to pay than those who use other means (traditional healers, herbalists). This variable is a nub factor for establishing community-based health insurance since the establishment of the community-based health insurance requires the frequent use of orthodox means of treatment. The heads of the household who are farmers/sellers are less willing to pay than those who are self employed or working in the private/public sector.

Insert Table 3 here.

The parametric mean WTP is approximately 1010 CFA francs/month/person or $\$ 2.15 /$ month/person.

\subsection{The mean WTP of the non parametric approach}

Non-parametric estimation offers an advantage to parametric estimation since it does not rely on the distributional assumptions made by the researcher. Furthermore, nonparametric models are more robust and offer greater flexibility in the shape of the response function, but they provide less economic information. Hence, we compute Turnbull estimator of WTP (Turnbull 1976) for community-based health insurance. In contingent valuation studies, respondents sometimes overstate their WTP, since the Turnbull is a lower bound estimate, it 
can be seen as a conservative estimate of WTP. Following Haab and McConnell (2002) and Bateman et al. (2002), the lower bound of the mean WTP for community-based health insurance is 659 CFA francs/month/person or $\$ 1.4 / \mathrm{month} /$ person.

Based on the two approaches (the non-parametric and parametric ones) the mean WTP for community-based health insurance ranges from $\$ 1.4 /$ month/person to $\$ 2.15 /$ month/person. This information is crucial for the policymakers and actuaries to set premiums that will not exceed the amount households in rural areas can afford to pay.

\section{Conclusions}

Many poor households in rural areas are excluded from the formal insurance. An alternative for these households which has proven to be effective at delivering adequate health care is the community-based health insurance. Nevertheless, developing this community-based health insurance from a policy perspective is relevant only if there is a potential demand for it. The overall objective of the study was to investigate the effects of the social capital on the demand for community-based health insurance. By means of a face-to-face contingent valuation survey, we explored this effect of the social capital on the demand for community-based health insurance. The results of our case study indicate that the social capital has a positive impact on WTP. This indicates that the degree of community solidarity is an important factor in establishing a community-based health insurance. As such, our findings coincide with those of other researchers that find that social capital has a positive and significant impact on the WTP for community based-health insurance (Zhang et al.2006). Hence, policymakers should strengthen the social ties in the community in an attempt to increase the enrolment rate and the demand for community-based health insurance in rural areas. This may improve the well being of the poor in rural areas who are most often exposed to deseases and poverty. Furthermore, age is also a determinant of WTP: younger people are more willing to pay as compared to older individuals. Thus, policymakers ought to subsidize or reduce the premiums of the older individuals in order to encourage them to be enrolled. Lastly, the mean WTP for community-based health insurance ranges from $\$ 1.4 / \mathrm{month} /$ person to $\$ 2.15 / \mathrm{month} /$ person, depending on the approach used.

\section{References}

Arrow, K., Solow, P. R., Leamer, E.E., Radner, R., \& Shuman, H. (1993). Report of NOAA panel on contingent valuation method. Federal Register, 58(10), 4601-4614.

Asgary, A., Willis, K. A., Taghvaei, A., \& Rafeian, M. (2004). Estimating rural households' willingness to pay for health insurance. European Journal of Health Economics, 5, 209-215.

Bateman, I. J., Carson, R. T., Day, B., Hanemann, M., Hanley, N., Hett, T., Jones-Lee, M., Loomes, G., Mourato, S., Ozdemiroglu, E., Pearce, D. W., Sugden, R. \& Swanson, J. (2002). Economic valuation with stated preference techniques: A manual. Cheltenham, UK: Edward Elgar.

Baum, F. (1997). Public health and civil society: understanding and valuing the connection. Australian and New Zealand Journal of Public Health, 21(7), 673-675.

Bishop, R., \& Heberlein, T. (1979). Measuring the values of extra-market goods: are indirect measures biased? American Journal of Agricultural Economics, 61,926-930.

Blumenschein, K., Blomquist, G. C., Johannesson, M., Horn, N., \& Freeman, P. (2008). Eliciting willingness to pay without bias: Evidence from a field experiment. Economic Journal, 118 (525), 114-137

Bose, A., \& Desai, P.B. (1983). Studies in social dynamics of primary health care. Delhi, India: Hindustan Publishing Company.

Bowles, S., \& Gintis, H. (2002). Social capital and community governance. The Economic Journal, 112(483), 419-436.

Bulte, E., Gerking, S., List, J.A., \& de Zeeuw, A. (2005). The effect of varying the causes of environmental problems on stated values: Evidence from a field study. Journal of Environmental Economics and Management, 49, 330-342.

Cameron, T.A. (1988). A new paradigm for valuing non-market goods using referendum data: Maximum likelihood estimation by censored logistic regression. Journal of Environmental Economics and Management, 15, 355-379.

Carrin, G., Waelkens, M. P., \& Criel, B. (2005). Community-based health insurance in developing countries: a study of its contribution to the performance of health financing systems. Tropical Medicine and International Health, 10, 799-811. 
Carson, R.T., and Flores, N.E., \& Meade, N.F. (2001). Contingent valuation: Controversies and evidence. Environmental and Resource Economics, 19(2): 173-210.

Carson, R.T. (2000). Contingent valuation: A user's guide. Environmental Science and Technology, 34, 1413-1418.

Coleman, J.S. (1990). Foundations of social theory. Cambridge, MA: Harvard University Press.

Coleman, J.S. (1988). Social capital in the creation of human capital. American Journal of Sociology, 94, 95-120.

Davis, R.K. (1963). Recreation planning as an economic problem. Natural Resources Journal, 3, 239-249.

Dror, M., Radermacher, R., \& Koren, R. (2007).Willingness to pay for health insurance among rural and poor persons: Filed evidence from seven micro health insurance units in India. Health Policy, 82, 12-27.

Flores, M., \& Rello, F. (2003). Social capital and poverty lessons from case studies in Mexico and Central America. ESA Working Paper No. 03-12. Food and Agricultural Organization, Italy.

Gottret, P., \& Schieber, G. (2006). Health financing revisited. A practitioner's guide. Washington, DC: World Bank.

Gustafsson-Wright, E., Asfaw, A., \& Van der Gaag, J. (2009). Willingness to pay for health insurance: An analysis of the potential market for new low-cost health insurance products in Namibia. Social Science and Medicine, 69(9), 1351-1359.

Haab, T. C., \& McConnell, K. E. (2002). Value environmental and natural resources: The econometrics of non-market valuation. Edward Elgar, Cheltenham, UK.

Hanemann, M., Loomis, W.J., \& Kanninen, B. (1991). Statistical efficiency of double-bounded dichotomous choice contingent valuation. American Journal of Agricultural Economics, 73, 1255-1263.

Hanemann, W.M., \& Kanninen, B. (1999). The statistical analysis of discrete-response CV data. In I.J., Bateman, \& K.C. Willis, (Eds.), Valuing environmental preferences: Theory and practice of the contingent valuation method in the US, EC, and developing countries, Oxford: Oxford University Press.

Hoehn, J.P., \& Randall, A. (1987). A satisfactory benefit cost indicator from contingent valuation. Journal of Environmental Economics and Management, 14, 226-247.

Hsiao, W. C. (2001). Unmet health needs of two billion: Is community financing a solution? HNP Discussion Paper. Washington DC. World Bank.

Kawachi, I., Kim, D., Coutts, A., \& Subramanian, S.V. (2004). Commentary: Reconciling the three accounts of social capital. International Journal of Epidemiology 33(4): 682-690.

Lin, N. (2000). Inequality in social capital, Contemporary Sociology, 29(6), 785-795.

Matul, M., McCord, M.J., Phily, C., \& Harms, J. (2009). The landscape of Microinsurance in Africa. Briefing Note No.1, International Labor Organization.

Mitchell, R.C., \& Carson, R.T. (1989). Using surveys to value public goods: The contingent valuation method. Washington DC: Resources for the Future.

Morrison, M., \& Brown, T. C. (2009). Testing the effectiveness of certainty scales, cheap talk, and dissonance-minimization in reducing hypothetical bias in contingent valuation studies. Environmental and Resource Economics, 44 (3), 307-326.

Portes, A. (1998). Social capital: its origins and applications in modern sociology. Annual Review of Sociology, 24, 1-24.

Putnam, R. (2000). Bowling alone: the collapse and revival of American community. New York: Simon and Schuster.

Putnam, R., Leonardi, R., \& Nanetti, R.Y. (1993). Making democracy work. Princeton, New Jersey: Princeton University Press.

Turnbull, B. W. (1976). The empirical distribution function with arbitrarily grouped, censored, and truncated Data. Journal of the Royal Statistical Society, 38(B), 290-295.

Wilkinson, R. G. (1996). Unhealthy societies: the afflictions of inequality. London: Routledge. 
Whittington, D. (1998). Administering contingent valuation surveys in developing countries. World Development, 26, 21-30.

Whittington, D. (2002). Improving the performance of contingent valuation studies in developing countries. Environmental and Resource Economics, 22, 323-367.

Woolcock, M. (2001). Microenterprise and social capital: A framework for theory, research and policy. Journal of Socio-Economics, 30, 193-198.

Woolcock, M., \& Narayan, D. (2006). Social capital: Implications for development theory, research, and policy revisited. In A. Bebbington, M. Woolcock, S. Guggenheim, \& E.A. Olson (Eds.), The search for empowerment. Social capital as idea and practice at the World Bank. Kumarian Press.

World Health Organization (2005). Achieving universal health coverage: Developing the health financing system. Technical briefs for policy-makers No. 1. Geneva.

Zhang, L., Wang, H., Wang, L., \& Hsiao, W. (2006). Social capital and farmer's willingness-to-join a newly established community-based health insurance in rural China. Health Policy, 76(2), 233-242.

\section{Notes}

Note 1. One drawback of the social capital is its measure. Up to date there is not a general consensus in the scientific community on how to measure the social capital. Most studies use the membership. Nevertheless there is a wide consensus about association membership as proxy of social capital.

Note 2. This was done to mitigate the hypothetical bias. This bias refers to the fact that respondents are not making real transactions and the willingness to pay (WTP) can be overestimated. This script explicitly informs the respondents they should consider that the results of the study will have an actual effect and that the respondents must integrate this before answering the valuation question.

Table 1. Description of the variables and summary statistics

\begin{tabular}{|c|c|c|c|c|c|}
\hline Variable & Description & Mean & $\begin{array}{l}\text { Standard } \\
\text { Deviation }\end{array}$ & Min & Max \\
\hline Bid1 & $\begin{array}{l}\text { First bids }(250,350,450,550,650,800 \mathrm{CFA} \\
\text { francs) }\end{array}$ & 510.40 & 184.89 & 250 & 800 \\
\hline Bid2 & Second bids & 850.31 & 422.28 & 125 & 1600 \\
\hline Yesno1 & First yes/no response ( 1 if yes, 0 otherwise) & 0.81 & 0.40 & 0 & 1 \\
\hline Yesno2 & Second yes/no response ( 1 if yes, 0 otherwise) & 0.58 & 0.50 & 0 & 1 \\
\hline Male & $\begin{array}{l}\text { Gender of the respondent ( } 1 \text { if the male, } 0 \\
\text { otherwise) }\end{array}$ & 0.62 & 0.48 & 0 & 1 \\
\hline Hfamily & $\begin{array}{l}\text { Family health status (percentage of individuals in } \\
\text { the household who were ill in the last } 9 \text { months) }\end{array}$ & 0.17 & 0.45 & 0 & 5 \\
\hline Knowledge & $\begin{array}{l}\text { Knowledge regarding the concept of community } \\
\text { health insurance ( } 1 \text { if know the concept, } 0 \\
\text { otherwise) }\end{array}$ & 0.27 & 0.44 & 0 & 1 \\
\hline Hhnumber & Number of people in the household(continuous) & 6.18 & 3.81 & 1 & 30 \\
\hline Catholic & Religion (1 if Catholic, 0 otherwise) & 0.59 & 0.49 & 0 & 1 \\
\hline Age & Age (number of years) & 42.39 & 12.42 & 22 & 82 \\
\hline Farmer & Profession ( 1 if farmers/sellers, 0 otherwise) & 0.53 & 0.50 & 0 & 1 \\
\hline Meanstreatment & $\begin{array}{l}\text { The means of seeking treatment when any } \\
\text { member of the household falls sick ( } 1 \text { if orthodox, } \\
0 \text { otherwise) }\end{array}$ & 0.83 & 0.38 & 0 & 1 \\
\hline Education & $\begin{array}{l}\text { Level of education of the respondent ( } 1 \text { if the } \\
\text { respondent has been to school at least } 7 \text { years, } 0 \\
\text { otherwise) }\end{array}$ & 0.94 & 0.23 & 0 & 1 \\
\hline Involvement & $\begin{array}{l}\text { Participation in a health policy and/or in an } \\
\text { association which aims at improving the health } \\
\text { status ( } 1 \text { if yes, } 0 \text { otherwise) }\end{array}$ & 0.55 & 0.50 & 0 & 1 \\
\hline Income & $\begin{array}{l}\text { Level of income ( } 1 \text { if equal or above average } \\
\text { income, } 0 \text { otherwise) }\end{array}$ & 0.16 & 0.37 & 0 & 1 \\
\hline
\end{tabular}


Table 2. Response to the assigned bids

\begin{tabular}{lll}
\hline Yesno1 & Yesno2 & \\
\hline & Yes (Yesno2 $=1)$ & No $($ Yesno2 $=0)$ \\
Yes $($ Yesno1 $=1)$ & $46.87 \%$ & $33.83 \%$ \\
No $($ Yesno1 $=0)$ & $10.78 \%$ & $8.52 \%$ \\
\hline
\end{tabular}

Table 3. Econometric estimation of the interval data model

\begin{tabular}{lll}
\hline Variable & Coefficient & Standard error \\
\hline & & \\
Age & $-8.86^{* * *}$ & 2.77 \\
HHnumber & 9.923 & 9.20 \\
Catholic & $178.46^{* *}$ & 74.07 \\
Male & 57.46 & 75.85 \\
Involvement & $177.56^{* *}$ & 72.93 \\
Hfamily & 10.54 & 88.49 \\
Knowledge & $141.99^{*}$ & 83.11 \\
Meanstreatment & $217.21^{* *}$ & 93.79 \\
Education & 136.00 & 114.70 \\
Income & $212.25^{*}$ & 105.42 \\
Farmer & $-120.68^{*}$ & 71.77 \\
Intercept & $767.70^{* * *}$ & 199.96 \\
\hline
\end{tabular}

$* * *, * *$ and $*$ mean significant at 1,5 and $10 \%$ respectively. 